\title{
XIII.
}

\section{OYSTER CULTURE AND CLAM FISHING, PRINCE EDWARD ISLAND.}

\author{
By Professor E. W. MacBrme, M.A., D. Sc., F.R.S., London, late Professor of Zoology, \\ McGill University, Montreal.
}

I arrived at Malpeque on Richmond or Malpeque bay on the north shore of Prince Ldward Island, on July 1, 1908, and remained there during the month of July. I had hoped to have had the cooperation of Captain Kemp and the SS. Ostrea, as had been arranged for by Professor Prince, the Dominion Commissioner of Fisheries, but owing to other arrangements this help was not forthcoming, and the scope of my work was very much curtailed. Owing to the kindness and cooperation, however, of the Honourable Peter McNutt, member of the cabinet of the Island Legislature, my visit ras to some extent redeemed from barrenness, and the results are briefly recorded helow.

The oyster fisheries of Prince Edward Island are carried on in a series of inlets of the sea, which are found all along the north coast of the island, and, to some extent, on the south coast as well. The structure of all these inlets is somewhat similar. They may be described as shallow inundations of portions of the island by salt water, and they are in each case shut off from the outer waters of the gulf by a sand-bar, through which a comparatively narrow channel admits the tide and also permits of the entrance of small vessels. The north coast of the island is wasting at a comparatively rapid rate under the combined influence of frost, rain and the waves of the sea. ${ }^{*}$ The farms on the north shore are thus being diminished in size, and to quote the expression used to me by one of the proprietors of such a farm, 'One year a field is ploughed, and the next it is over the cliff.' It is therefore probable that in the near future fresh inundations will occur and new bays be formed. The reason of the strikingly rapid waste of the land is the cutting down of the forests by which a hundred years ago the island was covered. The snow is thus exposed unprotected to the spring sun and melts rapidly, causing freshets which wash away large portions of the extremely soft red rock of which the island is composed. Another result of these freshets is the silting up of the shallower portions of the bay, by the sediment brought down by the freshets. Darnley basin, an eastern offshoot of Malpeque bay, was fifty years ago navigable for small vessels, and vessels were built beside its upper end and launched on it. Now, even at high tide, it is difficult to launch even a flat-bottomed boat on it. In very many places on these bays, where now no living oysters are obtained, deposits of 'oyster-mud' are found, which are dredged up in the winter time through holes in the ice, and sold to the farmers for manure. This oyster mud consists of layers of oyster shells and of muddy debris containing smaller fragments of shells, aggregating in some cases eighteen feet in thickness. As the soil of Prince Edward Island is very deficient in lime, this oyster mud is much sought after by the farmers for use as a fertilizer. Oyster mud deposits can only be interpreted as old oyster beds, which have been suffocated by the too rapid deposition of silt and subsequently buried out of sight by its continued accumulation. The numerous localities in which oyster mud

* No account is taken of the subsidence of the entire Atlantic coast area, the most important factor in this erosion. 
can be dredged point to a former extension of the oyster beds, far exceeding that which exists at the present day, or has existed during the last ten or twelve years.

But the evidence for the rapid diminution in the productiveness of the oyster-beds is not confined to theen deposits of oyster mud. Twenty years ago oysters were so nbundant and easly obiained, that they fetched only a price of one dollar per barrel. When sold by the fishermen five years ago the price was from five to seven dollars a barrel, whilst in 1907 ten to twelve dollars per barrel was paid for oysters to the fishert men. When I visited Prince Edward Island in 1903 one of the most valued beds was the Curtain Island bed, so called from its proximity to Curtain Island, an islet in Malpeque bay. In 1908 this bed was practically exhausted, and although Curtain Island oysters are still placed on the market, it appears that this appellation has become merely a name of certain type of oyster. Nearly all the somewhat meagre catch of 1907 was made in Chichester cove, one of the minor branches of Malpeque bay; but in 1908 when I visited this cove, the more accessible beds in shallower water were exhausted. Still more striking evidence of the depletion of the oyster beds may be obtained from Grenville bay, an inlet of the sea lying ten miles east of Malpeque bay, and of similar character, though of much smaller size. Oysters were formerly so abundant in this bay that sailing ships came from Cardiff and were laden solely with oysters; now the beds are so near depletion that very few barrels from the bay reach the market. It cannot be doubted that if present conditions continue, the fate which has over taken Grenville bay will, at no distant date, over take also Malpeque bay.

The Canadian oyster, Ostrea virginiana, is identical with the species which is so abundant along the eastern coast of the United States. Like so many other natural products this species is possessed of the finest flavour at the northern limit of its range, which is in Canada; if it should therefore be extirpated in Canada a most valuable national asset would be lost. Along the coast of the United States there has been, as in Canada, much depletion of the beds by overfishing, but there is a very important difference between the conditions in the United States and those in Canada. Should the oyster be completely extirpated at any locality on the coast of Virginia, for example, and the conditions remain the same, in the course of forty to fifty years, the oyster would re-appear, and new oyster beds ke formed, but if the oyster should be extirpated at any point in Canada, no such natural recovery is possible.

The rason for the difference is that Ostrea virginiana is essentially a southern species, and requires for the welfare of its 'spat,' or free-swimming larval stage, a temperature of awter of from seventy to eighty degrees Fahrenheit. Such a temperature is everywhere to be found during the summer along the coast of the southern United States. In the Gulf of St. Lawrence, on the contrary, the general summer temperature of the water does not rise much above forty degrees, and such cold water is fatal to the spat. The Canadian oyster is found only in such specially favoured spots where, owing to local conditions, the necessary temperature of the wuter is attained during the summer. As the 'spat' swim for about three weeks before they settle, ample opportunity is afforded for their wide distribution by means of currents, tidal and otherwise. Thus 'spat' fro n neighbouring areas would be carried into a depleted area, and settling down, wouin give rise to a fresh crop of oysters. 'This is what happens to depleted areas on the coast of the Southern States, but in Canada, when the 'spat' are carried into the cold waters of the gulf, they perish, and so one area cannot be restocked by the 'spat' from neighbouring areas.

Cultivation of oysters is successfully carried on in many parts of the world, and the question suggests itself why this should not be attempted in Prince Edward Island. The reasons why it has not been done in the past are economic and political, rather than natural. So long as all oyster beds were open to public tishing, it wonld pay no one to attempt to cultivate oysters, for he would be working merely for his neighbour's beneit. Nevertheless, the late United States consul at Summerside, made a successful attempt at cultivation, by having birch poles planted on the foreshore ncar his property. It appears that the Island Government raised objections to his. 
procedure, and that the poles, which had become covered with young oysters, were carried away by ice.

Quite recently, however, the Island Legislature has passed a law allowing the owner of a farm to obtain a lease of the shallow water near the shore adjacent to their farms, in order to cultivate oysters. In case the owner waives his right of seeking such a lease anyone else may apply for and obtain it. A few instances have oceurred of farmers seeking such leases, but in general they are deterred from embarking on the enterprise of oyster culture by want of knowledge and want of capital.

Under these circumstances, it seemed highly desirable that, I should begin an attempt to cultivate oysters this summer in order to give a practical demonstration of the method to be followed. By the kind co-operation of the Honourable Peter McNutt I was enabled to secure, on behalf of the Biological Stations of Canada, a lease of a portion of the waters of the 'Baltic,' adjacent to a farm belonging to $\mathrm{Mr}$. McNutt. The Baltic is a branch of the Darnley Basin, itself connected with Richmond or Malpeque bay. The Baltic is, however, closed off from Darnley basin by an embankment and bridge; there is little navigation in it and practically no fishing, and consequently, experiments begun in it are not liable to disturbance, as if they had been started in more exposed parts of the bay.

In order to initiate a new growth of oysters, a start may be made either with the free-swimming spat, or with "seed-oysters," i.e., oysters a year old, which are transplanted to the ground it is desired to stock. Owing to the absence of the SS. Ostrea, and to the fact that when I was in the island, all the available boats were employed in the lobster fishery, I was unable to obtain seed-oysters, the best locality for which is Ram Island, some miles out in the bay, and I therefore determined to try to catch the spat. For this purpose, birch poles about ten feet long were firmly fixed in the bottom of the leased area. The poles were planted in groups of three, the members of each group being close together, within six inches of each other, in fact. The several groups were arranged in lines at right angles to the shore, each group being six feet apart from the next group. In some cases, twigs were left on the poles, and as each group of poles produces a little eddy in the current as it sweeps past, it is hoped that the spat will settle on them in great quantities.

The result of the experiment will not declare itself until next year, but if it is successful, the poles should be covered with seed oysters. These will be allowed to grow on the poles for another year, when they will be removed by scraping off the bark. They can then be laid on suitable ground, and should be ready for market in another two years. About one hundred and twenty poles such as have been described, were planted. A somewhat similar experiment was tried in 1903, when the Biological Station was located at Malpeque. This experiment failed because the poles were planted in too shallow water, and they were carried away by the ice in the spring. For all such experiments it is important to bear in mind that there may be as much as three feet of ice in Malpeque bay in the winter, and consequently the poles must be sunk at such a depth that their tops are at least three feet below low water mark. This was mcst carefully attended to.

Different varieties of oysters from Prince Edward Island are offered in the market, the most highly-priced variety being the so-called 'cup-oyster' or Curtain Island oyster, in which the breadth is considerable, the upper valve flat, and the edge in one plane, this being the plane of the upper valves. Less valuable are 'mud-oysters,' in which the edge is curved upwards, so as to make opening difficult. 'The oysters from Grenville bay were very long and narrow. These differences seem to be the results partly of the ground on which the oysters lie, and partly of the degree of crowding amongst adjacent oysters. If the oysters are fairly widely spaced, and lie on comparatively hard ground, where the deposition of silt is slight, they will grow into the much-prized 'Curtain Island' type. If they lie on soft ground, where the deposition of silt is rapid, they will, if they survive at all, develop into mud-oysters.- 'The upward growth of the edges of the shell is a struggle to keep the apertures of the valves above the leve] of the silt. Finally, if oysters are crowded together, they will grow 
long and narrow, each individual striving to bring the aperture of his shell-valves above and beyond those of his neighbours. The ground leased by the biological stations is comparatively clean, hard ground, and I hope to be able, when the seedoysters have been removed from the poles, to rear them into oysters of the "Curtain Island' type.

All the bays on the north coast of Prince Edward Island would be natural breeding grounds for the oyster, and were these under proper supervision and control, it would be a conservative estimate to say that the production of Prince Edward Island oysters could be increased one hundred-fold.

The question of the protection of the oyster beds is a serious one. I believe I am correct in stating that while the jurisdiction rests with the Dominion government, the ownership of these fisheries is vested in the Island government. Owing to the shallowness of the waters, the oysters are easily accessible to unprincipled persons, espe:ially in winter, when they can be reached through holes in the ice. In one case known to me, a cultivator had given up his experiment, not because it was unsuccessful, but because his oysters were robbed by his neighbours. Wie must hope for the growth of a more enlightened public opinion and a better policing system, both of which advantages could probably be obtained, were oyster cultivation more generally undertaken.

There were considerable complaint when I arrived in the island, about the damage done to the oyster beds by fishing for the hard-shelled or little-neck clam, Venus mercenaria. The fishery of this clam is of comparatively recent growth, and it is lawful during part of the close season for oysters. The hard-shelled clam, unlike the oyster, does not lie flat on the ground on which it feeds, but is always found buried in the mud at the bottom, the posterior surfaces of the edges of the valves just showing akove the silt. It is fished for by means of a great rake with teeth nine inches long. To the end of the shaft where it joins the T-piece which supports the teeth, iron netting is attached. With this rake great lumps of the bottom are pulled up. 'I'hese fragments are then sifted on the iron netting, the mud flows away in the water and the clams are obtained free from mud on the netting. Were such an instrument to be used on an oyster bed, its effect would be in every way disastrous. But there is no excuse for fishing for these shell-fish on oyster beds. The characteristic ground in which they flourish is blue mud, which is unsuitable for oysters. IMoreover, although those large specimens termed 'bulls' are to be found around the edges of oyster beds, they are not saleable. The demand is entirely for half-grown specimens, and the reason for this is obvious when the anatomy of the animal is taken into account. The oyster owes its edibility largely to the fact that, owing to its remaining in one spot once the adult condition is attained, the characteristic molluscan organ, the muscular foot, is not developed. But the clam can and does move slowly thrrugh the silt in which it lives, and the 'foot' is therefore well developed. As the clam increases in size the foot grows tougher, and hence the unsaleable character of full-grown specimens. That such specimen should be found in the oyster beds at all, I can oniy attribute to the circumstances that oyster beds tend to grow at their edges, new oysters settling on the shells of the old ones, and that in this way an oyster bed originally started on hard ground, can spread on to soft ground, inasmuch as it prepares in the shells of the old oysters a substratum for the further growth. In this way an area of blue clay may be invaded, and if this has already a population of Venus mercenaria the old individuals may survive, keeping open for themselves crevices between the growing. oyster shells, although no new hard-shelled clams can establish themselves there.

There is therefore no reason why oyster fisheries and hard-shelled clam fisheries should not exist side by side without mutual injury to one another, provided that the areas for each are defined.

I opened a considerable number of hard-shelled clams, but in none could detect any reproductive elements, from which $I$ conclude that the month of July does not form part of the breeding season. 